\title{
Development and Impact Behaviors of FRP Guarder Belt for Side Collision of Automobiles
}

\author{
Yoshio Aoki ${ }^{1}$, Akihisa Tabata ${ }^{1}$, Kotaro Nakamura ${ }^{1}$ and Goichi Ben ${ }^{2}$ \\ 1. Precision Machinery Engineering, Nihon University, Funabashi 274-8501, Japan \\ 2. Mechanical Engineering, Nihon University, Narashino 275-8575, Japan
}

Received: May 07, 2014 / Accepted: May 27, 2014 / Published: July 25, 2014.

\begin{abstract}
In automobiles, the CFRP (carbon fiber reinforced plastics) has a possibility of weight reduction in automotive structures which can contribute to improve mileage and then reduce carbon dioxide. On the other hand, the safety of collision should be also made clear in the case of employing the CFRP to automotive structures. In this paper, the CFRP guarder belt equipped in the automotive door is developed and examined by an experiment and a numerical analysis for replacing the conventional steel door guarder beam. As the experimental relation of impact load to displacement for CFRP guarder belt agreed well with that of numerical result, the numerical method developed here is quite useful for estimating impact behaviors of CFRP guarder belt.
\end{abstract}

Key words: Impact behavior, FRP, absorbed energy, automobile, collision safety, FEM (finite element model).

\section{Introduction}

It is well known that $\mathrm{CO}_{2}$ emissions, which are one of the greenhouse gases emitted from passenger vehicles such as automobile, are major cause of global warming. In the automobile industry, to reduce $\mathrm{CO}_{2}$ emissions, it is well known that the most effective method is to produce the fuel efficient automobile. To increase the fuel efficiency of the automobile, the most effective approach is to reduce the automobile weight by using lightweight material such as composite materials. FRP (fiber reinforced plastics) have been widely used in aerospace, industrial goods and other application fields because of their high specific strength and high specific modulus compared with metal. This means that the FRP contributes to lighten automobiles greatly. Otherwise, the safety of automobiles is also very important and the collision safety of the automobile has been evaluated by full

Corresponding author: Yoshio Aoki, Ph.D., professor, research fields: structural mechanics, safety design, structural health monitoring and strength of material. E-mail: aoki.yoshio@nihon-u.ac.jp. flap frontal crash, offset frontal crash and side impact tests. In the frontal crash test, it is possible to absorb the energy by largely deforming the front part and the rear. With an increasing an interest in the lightening of the automobile and in the securing the safety of passengers, many researches for them have been performed [1-9]. However, in the side impact test, it is hard to absorb the energy similarly, because of being very narrow for the survival space of passengers. In the inside of the door, a reinforcement member as shown in Fig. 1, namely door guarder beam made of steel has been installed to absorb impact energy and its deformation is limited to about $150 \mathrm{~mm}$.

In this study, the FRP door guarder belt is developed for the purpose of designing impact energy absorption members under side collision as shown in Fig. 2. A drop weight impact tests are carried out to investigate impact response behaviors and impact energy absorption characteristics of the FRP door guarder belt. Also, a FEM (finite element model) was developed to simulate the impact response behavior and the absorbed energy of the FRP door guarder belt under impact loading. 


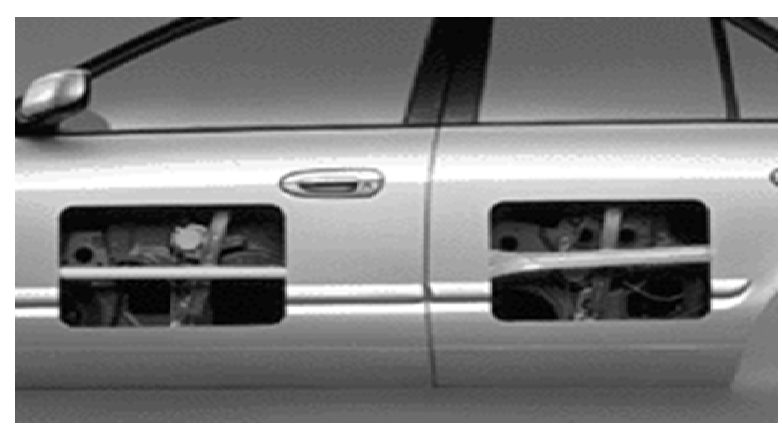

Fig. 1 Conventional door guarder beam.

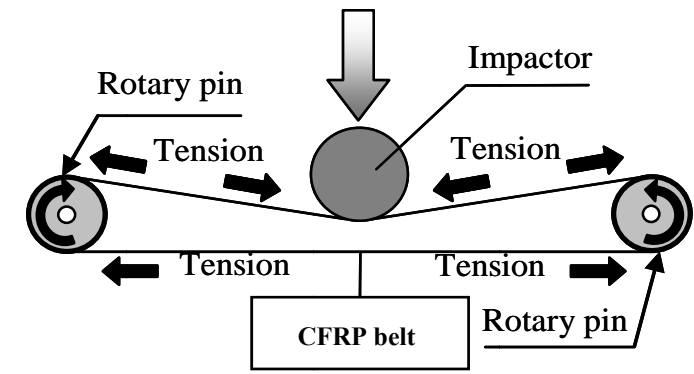

Fig. 2 Energy absorption mechanism of FRP guarder belt.

\section{Experiment}

\subsection{Experiment: Specimen Fabrication}

Fig. 2 shows the schematic diagram of the impact energy absorption by the FRP guarder belt. The impact energy is effectively absorbed by installing the FRP belt between two free fulcrums for the rotation and changing the vertical impact load of the falling weight to the tensile load. In order to prevent fracture in the support edge of specimen due to the stress concentration, a belt-shaped specimen was adopted. Thin FRP belt specimens were manufactured from unidirectional prepregs (T700SC/epoxy and RX350G125S/epoxy) by using the sheet winding method and its width and length were $50 \mathrm{~mm}$ and 1,642 mm, respectively. Fig. 3 and Table 1 show an FRP guarder belt specimen and the specimen's thickness and the mass.

\subsection{Tower Drop Weight Impact Test}

In order to evaluate the capacity of crash energy absorption and to show the micro and macro fracture behavior of the FRP guarder belt, the large size of drop tower facility for the impact test was designed as shown in Fig. 4. The FRP guarder belt was received

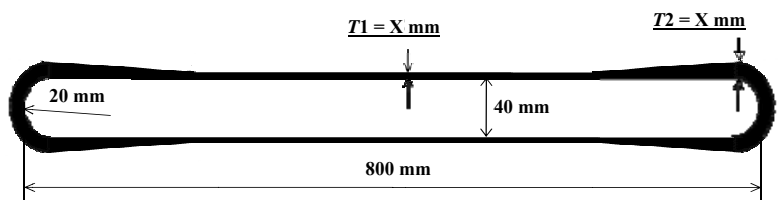

Fig. 3 FRP guarder belt specimen.

Table 1 Thickness, mass and material sequences of specimens.

\begin{tabular}{llll}
\hline & $\begin{array}{l}\text { Thickness } \\
\text { T1/T2 }(\mathrm{mm})\end{array}$ & Mass (g) & Carbon fiber \\
\hline A-Type & $0.9 / 1.2$ & 102 & T700SC \\
B-Type & $0.4 / 0.7$ & 56.5 & RX350G125S \\
\hline
\end{tabular}

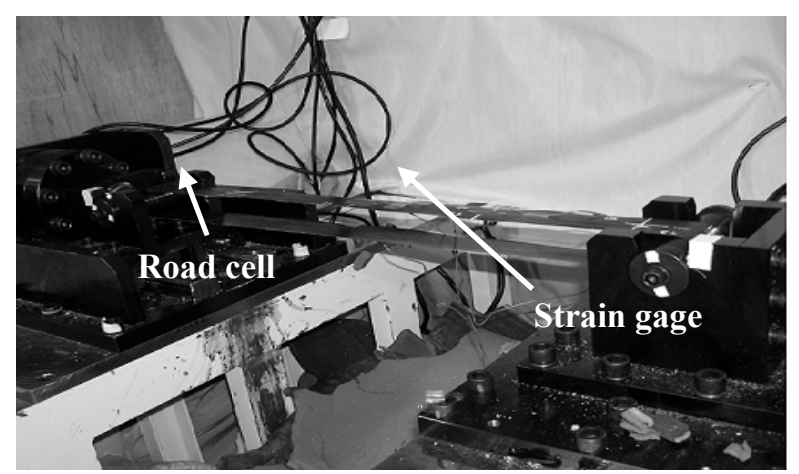

(a) Mounted specimen

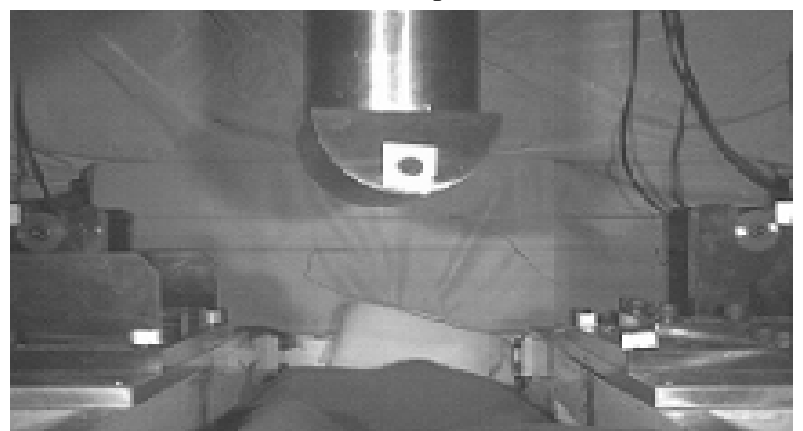

(b) Impactor

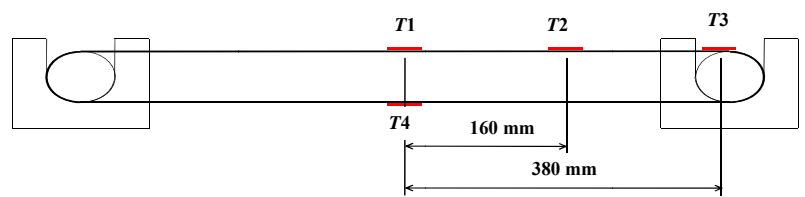

(c) Measured location of the longitudinal strain

Fig. 4 Tower drop impact test setup.

the impact load generated by a free drop weight of 100 $\mathrm{kg}$ from $12 \mathrm{~m}$ height. Therefore, the impact speed was approximately $55 \mathrm{~km} / \mathrm{h}$ just before the impact. The shape of impactor was a half cylinder having $100 \mathrm{~mm}$ radius and $200 \mathrm{~mm}$ width. The impact load of the 
specimen was measured by a load cell installed behind the rotary pin. In order to investigate the fracture mechanism of the FRP guarder belt, a high-speed camera was chosen. And the dynamic strain of the specimen from collision to fracture was measured by a strain gauge. The strain gauge stuck on three places at the center of the specimen as a collision point ( $T 1)$, near the rotary pin (T3) and middle point of both (T2) as shown in Fig. 4c. The FRP guarder belt specimen supported both ends in the rotary pin of a diameter of $40 \mathrm{~mm}$. Fig. 5 shows the observed fracture modes and the fracture location of FRP guarder belt specimen. In the experiment, the observed fracture mode was fiber breakage in the entire width of FRP belt specimen due to the tensile load acted on the whole the specimen. And the specimen fractured at their center or supported edge, which is larger tensile stress, occurred at impact location or around the rotary pin is supposed.

\section{Results and Discussions}

In the case of side collision, there is the collision from diagonal direction actually. Therefore, the impact response behavior for the side collision with offset angle of FRP guarder belt was examined. The experiment of the side collision with offset angle was performed to incline the supported base of the specimen so that the impactor hit the specimen diagonally as shown in Fig. 6. The drop weight impact test with offset angle of $15^{\circ}$ was carried out in this experiment (offset impact test), then the difference in impact response behavior of the side collision was examined. Fig. 7 shows relation of the experimental impact load to displacement of the three FRP guarder belts for vertical and offset impact. The experimental impact load increase with increasing the displacement of FRP belt specimen nonlinearly, then, they become the maximum value just before fracture. In the case of A-type specimen, the impact load recovered to $75 \mathrm{kN}$ at the displacement of about $100 \mathrm{~mm}$ within the time of $6-7 \mathrm{~m} / \mathrm{s}$. On the other hand, the B-type specimen fractured by maximum load about $32 \mathrm{kN}$. The measured load-displacement curve for the vertical

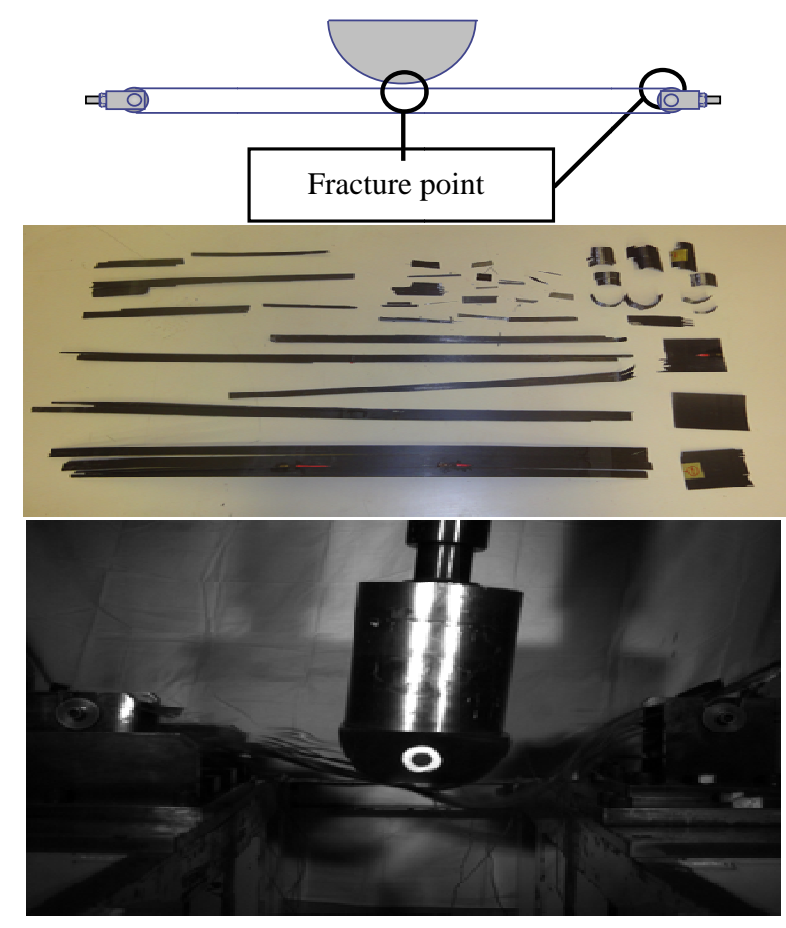

Fig. 5 Fracture mode of the specimen in the impact test.

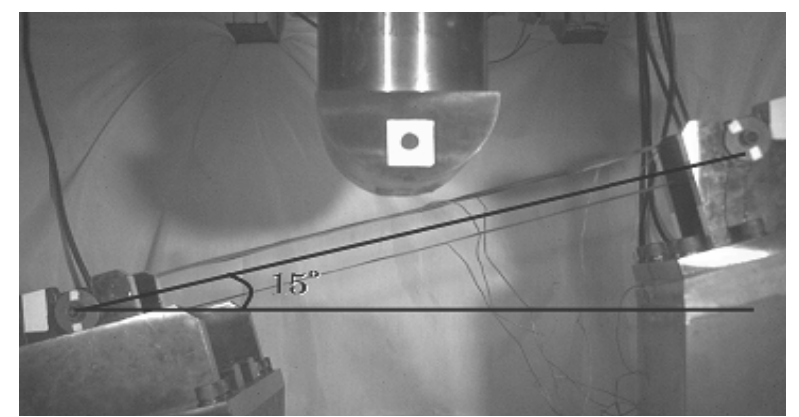

Fig. 6 The drop weight impact test with offset angle of $15^{\circ}$.

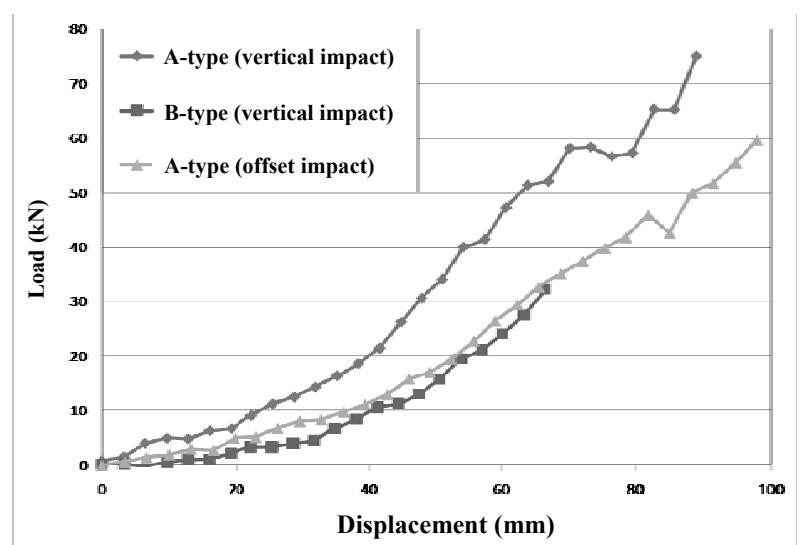

Fig. 7 Comparison of experimental load-displacement curve for FRP guarder belt. 
impact test and the offset ones became an almost similar tendency.

Next, the specific absorbed energy divided by the individual weights of the FRP guarder belt was compared with the conventional steel impact beam shown in Table 2. The absorbed energy of CFRP guarder belt can be calculated by an area of the curve of an impact load $P$ and a displacement of the impact location of the specimen until its fracture as

$$
E(\delta)=\int P(\delta) \mathrm{d} \delta
$$

The conventional impact beam consists of steel pipe and has diameter of $35 \mathrm{~mm}$, thickness of $2 \mathrm{~mm}$ and length of $945 \mathrm{~mm}$. The experimental energy absorption of FRP guarder belt is bigger than it of the conventional impact beam and the specific energy absorption of the FRP belt is 22 times bigger than it of the impact beam. And Table 3 shows the comparisons of fracture load/displacement/time and energy absorption of FRP guarder belt. The energy absorption of A-type specimen became three times or more it B-type specimen.

Figs. 8-10 show the experimental impact strain variations at four locations in the specimen. The strain of each locations increase with time transit nonlinearly. The strain became maximum around the corner pin in B-type specimen by which a local breaking due to the stress concentration becomes predominant though the strain became maximum at the center of the specimen in A-type specimen by which fiber breakage becomes predominant. In the offset impact, it is possible that the strain variation of $T 1$ and $T 2$ almost same that the tensile force influences by the friction when the impactor contact.

Table 2 Comparisons of absorbed energy for FRP guarder belt and steel impact beam.

\begin{tabular}{lll}
\hline & $\begin{array}{l}\text { Absorbed } \\
\text { energy }(\mathrm{J})\end{array}$ & $\begin{array}{l}\text { Specific absorbed } \\
\text { energy }(\mathrm{kJ} / \mathrm{kg})\end{array}$ \\
\hline $\begin{array}{l}\text { FRP guarder belt } \\
\text { (A-type) }\end{array}$ & 2,800 & 27.50 \\
$\begin{array}{l}\text { Steel impact beam } \\
\text { (1,900 }\end{array}$ & 1.243 \\
\hline
\end{tabular}

Table 3 Comparisons of fracture time and energy absorption of FRP guarder belt.

\begin{tabular}{lllllllll}
\hline $\begin{array}{l}\text { Experimental } \\
\text { condition }\end{array}$ & $\begin{array}{l}\text { Types } \\
\text { specimen }\end{array}$ & $\begin{array}{c}\text { of Fracture load } \\
(\mathrm{kN})\end{array}$ & $\begin{array}{l}\text { Fracture } \\
\text { displacement } \\
(\mathrm{mm})\end{array}$ & $\begin{array}{l}\text { Fracture } \\
(\mathrm{m} / \mathrm{s})\end{array}$ & $\begin{array}{c}\text { time Absorbed } \\
\text { energy }(\mathrm{J})\end{array}$ & $\begin{array}{l}\text { Mass } \\
(\mathrm{g})\end{array}$ & $\begin{array}{l}\text { Ratio } \\
\text { energy }(\mathrm{kJ} / \mathrm{kg})\end{array}$ & $\begin{array}{l}\text { absorbed Fracture } \\
\text { location }\end{array}$ \\
\hline $\begin{array}{l}\text { Vertical } \\
\text { impact }\end{array}$ & A-type & 75 & 98 & 6.5 & 2,800 & 102 & 27.5 & $T 1$ \\
Offset impact & B-type & 32 & 66.5 & 4.5 & 670 & 56.5 & 11.8 & $T 2$ \\
\hline
\end{tabular}

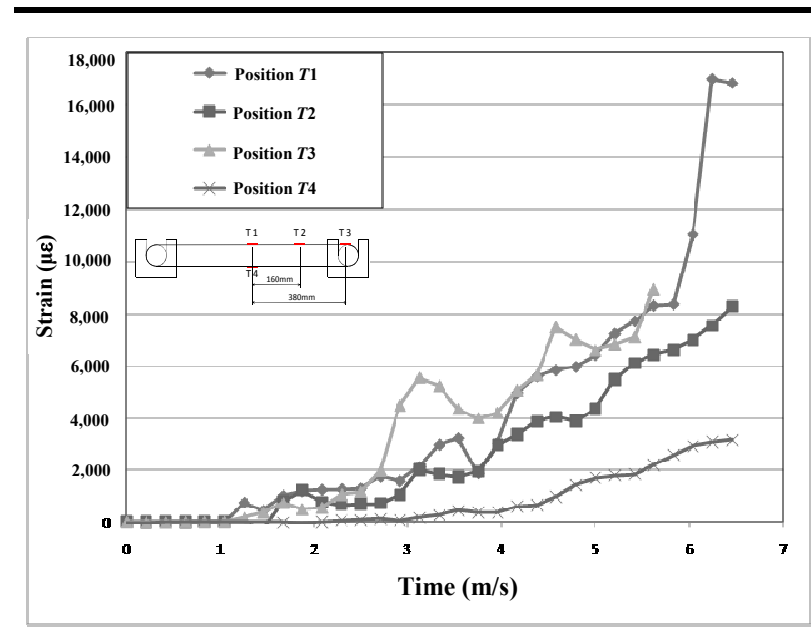

Fig. 8 Strain of A-type specimens for vertical impact.

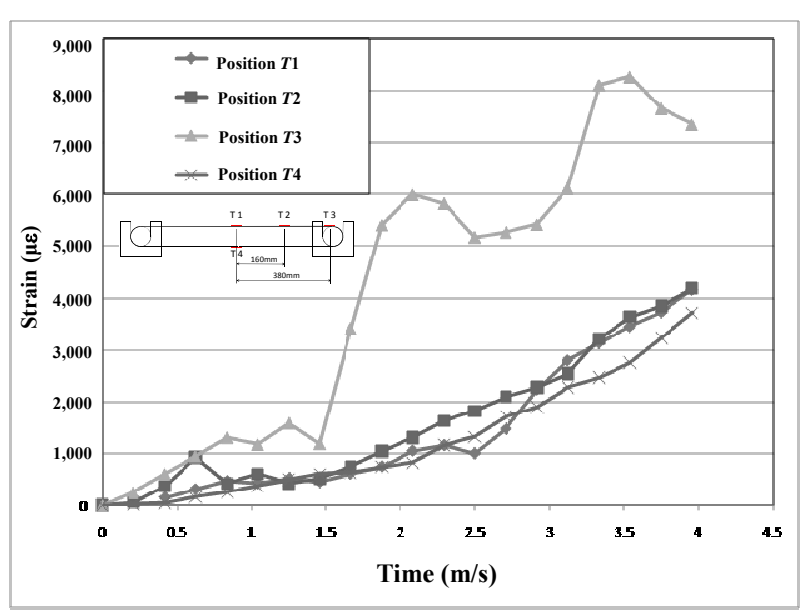

Fig. 9 Strain of B-type specimens for vertical impact. 


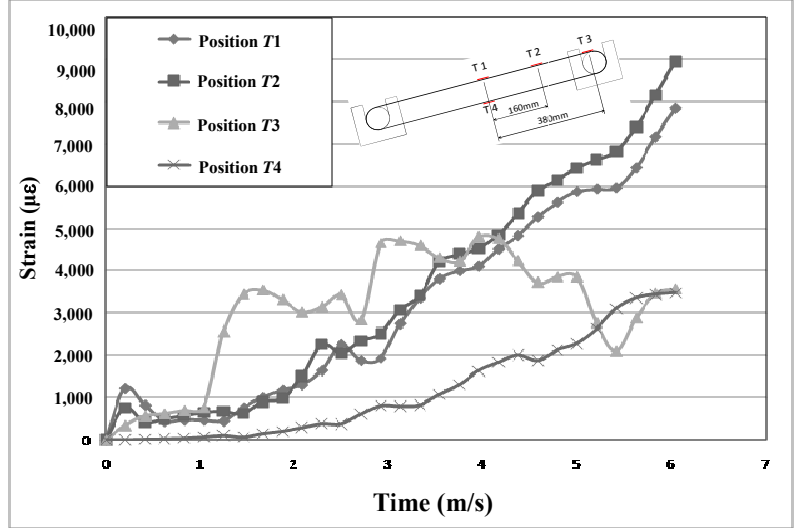

Fig. 10 Strain of A-type specimens for offset impact.

\section{Conclusions}

The FRP guarder belt was developed for the purpose of designing impact energy absorption member under side collision. The drop weight impact tests were carried out and the impact response behavior and the absorbed energy of the FRP door guarder belt under impact loading were examined. From these results, we could be concluded as below:

(1) The FRP guarder belt absorbed crash energy along the entire length of it and tension stress is applied on both the upper and lower side of belt;

(2) The experimental energy absorption and the specific energy absorption of FRP guarder belt are bigger than it of the conventional impact beam;

(3) The impact response behavior and impact strength of the FRP guarder belt were obtained by the tower drop weight impact test.

The CFRP guarder belt contributes to lightweighting and safety improvement of safety of the car body greatly is supposed.

\section{References}

[1] Ben, G., Aoki, Y., and Sugimoto, N. 2010. "Development of Simulation Technology for Impact Behavior of CFRP/Al Alloy Hybrid Beams in Side Collision of Automobiles.” Advanced Composite Materials 19 (4): 363-79.

[2] Caliskan, A. G. 2002. “Axial \& Lateral Impact Prediction of Composite Structures Using Explicit Finite Element Analysis.” Presented at the ASME International Mechanical Engineering Congress \& Exposition, Louisiana, USA.

[3] Kim, H. S., Ben, G., Aoki, Y., and Shikada, A. 2005. "Comparison of FEM Results with Experimental Ones for FRP Tubes in Automobiles under Impact Load.” Presented at the 5th Japan-Korea Joint Symposium on Composite Materials, Korea.

[4] Kim, K. J., and Won, S. T. 2008. "Effect of Structural Variables on Automotive Body Bumper Impact Beam.” International Journal of Automotive Technology 9: 713-17.

[5] Cheon, S. S., Dai, G. L., and Kwang, S. J. 1997. “Composite Side-Door Impact Beams for Passenger Cars." Composite Structures 38 (1-4): 229-39.

[6] Thornton, P. H., and Jeryan, R. A. 1988. "Crash Energy Management in Composite Automotive Structures.” International Journal of Impact Engineering 7 (2): 167-80.

[7] Schmueser, D. and Wickliffe, L. E. 1987. "Impact Energy Absorption of Continuous Fiber Composite Tubes." Journal of Engineering Materials and Technology 109: 72-7.

[8] Ramakrishna, S. and Hamada H. 1998. "Energy Absorption Characteristics of Crash worthy Structural Composite Materials.” Engineering Materials 141-143: 585-620.

[9] Farely, G. L. 1983. "Energy Absorption of Composite Materials.” Journal of Composite Materials 17: 267-79. 